\title{
REFLEXÕES SOBRE O ENSINO CONTEMPORÂNEO: REALIDADE E VIVÊNCIA
}

\author{
REFLECTIONS ON CONTEMPORARY TEACHING: REALITY AND \\ EXPERIENCE
}

\author{
Cleidson Teixeira Vinhas ${ }^{1}$ \\ Vinícius Peter Schneider ${ }^{2}$ \\ Clóvis Dilli3 \\ Cristiano Telles Ginar ${ }^{4}$
}

\begin{abstract}
RESUMO: Esse trabalho tem por objetivo ressaltar as minhas experiências sobre o contexto da educação contemporânea. A educação visa propiciar condições para analisar e refletir criticamente sobre a realidade do ensino, o papel do educador reflexivo, investigador da própria ação, além de propiciar a vivência do cotidiano da escola como prática pedagógica e ética profissionalizante. Nesse trabalho, relato minhas experiências e pensamentos em relação á situação da educação na atualidade, e, sobretudo mostro uma reflexão acerca dessa experiência e sua importância para o desenvolvimento das competências necessárias para o exercício da profissão de orientador.
\end{abstract}

Palavras-chave: Ensino. Educação. Realidade. Vivências.

ABSTRACT: This work aims to highlight my experiences in the context of contemporary education. Education aims to provide conditions to analyze and critically reflect on the reality of teaching, the role of the reflective educator, investigator of the action itself, in addition to providing the experience of the school's daily life as a pedagogical practice and professional ethics. In this work, I report my experiences and thoughts in relation to the situation of education today, and, above all, I show a reflection on this experience and its importance for the development of the necessary skills for the exercise of the profession of advisor.

Keywords: Teaching. Education. Reality. Experiences.

RESUMEN: Este trabajo tiene como objetivo resaltar mis experiencias en el contexto de la educación contemporánea. La educación tiene como objetivo brindar condiciones para analizar y reflexionar críticamente sobre la realidad de la enseñanza, el rol del educador reflexivo, investigador de la acción misma, además de brindar la experiencia de la vida cotidiana de la escuela como práctica pedagógica y ética profesional. En este trabajo, relato

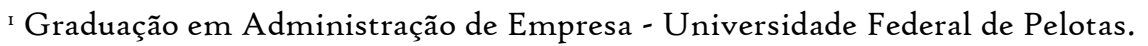

${ }^{2}$ Graduação em Direito - Univerisidade Federal de Santa Maria.

${ }^{3}$ Graduação em Tecnologia de Processos Gerenciais - Centro Universitário Uninter.

${ }^{4}$ Graduação em Engenharia de Controle e Automação - Universidade Federal de Pelotas.
} 
mis experiencias y pensamientos en relación a la situación de la educación en la actualidad $\mathrm{y}$, sobre todo, muestro una reflexión sobre esta experiencia y su importancia para el desarrollo de las habilidades necesarias para el ejercicio de la profesión de asesor.

Palabras clave: Docencia. Educación. Realidad. Experiências.

\section{UM OLHAR SOBRE A EDUCAÇÃO COMO PRÁTICA PEDAGÓGICA}

Os conceitos acerca de ensino têm mudado muito nas últimas décadas. Educar deixou de ser memorização de fórmulas e conceitos. Mas, mesmo assim, alguns professores continuam repassando aos alunos exercícios de um caderno amarelado com o passar do tempo. Esse método, ainda utilizado e propagado por alguns educadores, provou ser ineficaz, pois o não aprender, os conteúdos tornam-se suscetíveis de serem esquecidos pelos alunos - e além, claro, pelo fato deste método ser mais fácil para o professor que o utiliza, corrigir questões apenas pela resposta do que analisar o desenvolvimento de um aluno.

A educação como conhecemos encontra-se defasada e decadente, não apenas pelo fato anteriormente citado, mas pela desmotivação do orientador, a falta de investimentos pelos órgãos competentes, o não apôio comunitário familiar, que delegam toda a formação para a escola.

Então, mudanças são necessárias, mas nos perguntamos: o que é educação? Qual a sua finalidade e obrigações e necessidades?

Ao entrar em um novo século, a formação de professores torna-se elementar para essas mudanças na educação. Nunca, em cursos de licenciatura, ouviu-se tanto a palavra renovação como nos dias atuais.

Qualquer pessoa tem, mentalmente, seu significado, mas exprimir em palavras um conceito tão amplo torna-se difícil. Ao invés de empiricamente transmitir conteúdos aos alunos, a missão dos educadores nesses novos tempos muda bastante. Educar é inserir, inserção essa no cotidiano e no mundo.

$\mathrm{Na}$ escola atual vale a lei do aqui e agora. $\mathrm{O}$ aluno produz, o professor avalia e a nota sai. Todos os resultados têm de ser imediatos. Um currículo que até hoje é seguido 
rigidamente, muitas vezes é visto sem utilidade, sem conexão com a realidade dos alunos. Fato esse é um dos que mais origina a evasão escolar.

$\mathrm{Na}$ concepção diretiva, algumas vezes, tem-se que o aluno não deve pensar, mas sim obedecer. Ainda hoje somos orientados a reproduzir conteúdos e conhecimentos, mas não somos desafiados e nem incentivamos o pensamento, nem seu posicionamento na sociedade. Pois, a partir do momento que o aluno pensa, ele torna-se apto a contestar, podendo contestar o sistema. E esse método tende a persistir simplesmente por ser mais fácil. É mais fácil dispor de uma fórmula no quadro e os alunos obterem resultados a partir dela, do que fazer com que os alunos descubram a fórmula e em algumas vezes achem resultados a partir de suas descobertas.

Boa parte dos livros didáticos não favorece uma situação propícia ao ensino. Cada vez mais multicoloridos, com a função de atrair os alunos, poucos são os que realmente instigam os alunos a raciocinar e desenvolver situações-problema. Simplesmente, baseiamse em mascarar a realidade.

O ensino de matemática é um dos que mais oferece obstáculos à aprendizagem. A matemática é vista como chata, cansativa e sem utilidade. A matemática sempre foi ensinada mecanicamente: segue-se um exemplo e a partir deles, os alunos seguem um modelo. A grade curricular prega a aplicação de fórmulas e a resolução de situações problema.

De um bom professor, espera-se de acordo com os Parâmetros Curriculares Nacionais (PCN): “... desenvolvimento do pensamento numérico, algébrico, geométrico, métrico, combinatório... por meio da exploração de situações de aprendizagem...”.

Ensinar é inovar e desprender-se de falsos mitos. Parece que a teoria só existe em uma sala de aula. Ao sair da escola, tudo o que aluno ouve dentro dela desaparece. As áreas não existem mais, as formas geométricas parecem ser só figuras diferentes de tudo o que já foi visto antes.

Sendo o professor um alicerce fundamental da educação e formação do cidadão, cabe ao mesmo mudar sua postura e suas concepções em relação ao ensino e a realidade do 
aluno. Rogers afirma que: "é por meio de atos que se adquire aprendizagem mais significativa...”.

A realidade vivida pelo aluno é diferente da matemática da escola, e cabe ao professor promover a interação entre aluno e conteúdo. "Ninguém educa ninguém, ninguém educa a si mesmo, os homens se educam entre si, mediatizadas pelo mundo" (FREIRE, 1987)

Quanto à avaliação do aproveitamento de um aluno em relação ao desempenho, cremos que no ensino, os professores ficam de mãos atadas, devido o sistema escolar exigir um resultado expresso quantitativamente, então a prova surge como uma das únicas maneiras eficientes de se avaliar. Diferentemente de todas as outras disciplinas, em que há um vasto leque de opções de como avaliar, na matemática isso se torna difícil. Enquanto no ensino de língua portuguesa, por exemplo, pode-se avaliar todo o conhecimento de um aluno (tanto gramatical como argumentativo) com uma produção textual, já a matemática peca pela exatidão. Uma equação pode não ter uma única forma de resolução, mas sua resposta é única.

A prova pode passar de ameaça e tortura a um elemento motivador da aprendizagem. Não encaro a avaliação como uma forma de pressionar ou de traumatizar o aluno, mas sim com uma forma de confirmar, segundo a ótica do sistema vigente, o que o aluno abstraiu em seus passos. Pois, a avaliação do desempenho do discente sempre será classificatória, desde uma avaliação por trabalhos ou provas.

A escola mudou muito com o passar do tempo. Passou a ser uma extensão da casa (no mal sentido): professores são chamados de "tios e tias", generalizando a desordem familiar. Antes de ter uma relação de amizade, tem de haver, entre aluno e professor, principalmente, uma relação de respeito. Além disso, não devemos nos preocupar somente com o conhecimento através da absorção de informações, mas também pelo processo de construção do conhecimento e pensamento do aluno.

Conseqüentemente, para que isto ocorra, é necessária a conscientização do docente de que seu papel é de mediador aluno-conhecimento. Nos cursos de licenciatura sempre somos bombardeados com a mesma frase: "temos que formar mais que alunos, 
temos que formar cidadãos”, mas, como formaremos cidadãos críticos, pensantes e que saibam interagir no meio em que vivem, se nem na própria sala de aula a autoridade do professor é respeitada?

Realmente, não podemos pensar que a construção do conhecimento é entendida como individual. O conhecimento é produto da atividade e do conhecimento humano marcado social e culturalmente. $\mathrm{O}$ papel do professor consiste em agir com intermediário entre os conteúdos da aprendizagem e a atividade construtiva para assimilação.

Além disso, não devemos nos preocupar somente com o conhecimento através da absorção de informações, mas também pelo processo de construção do conhecimento e pensamento do aluno. Para que isto ocorra, é necessária a conscientização do professor de que seu papel é de mediador aluno-conhecimento.

Logo, a relação entre professor e aluno depende, fundamentalmente, do ambiente estabelecido pelo professor, da uma boa convivência com seus alunos, ouvir, refletir e discutir seus métodos com eles.

Antes muito temida hoje a reprovação é tida como raro: "Repetir o ano era o horror dos horrores. Para a meninada de hoje isso deve soar quase irreal" (LUFT, 2006).

Resultados tão desastrosos mostram muito mais do que a má formação de uma geração de professores e estudantes: evidenciam o pouco valor dado ao conhecimento matemático e a ignorância em que se encontra a esmagadora maioria da população no que tange a matemática. Não é por acaso que o Brasil conta com enormes contingentes de pessoas privadas da cidadania por não entenderem fatos simples de seu próprio cotidiano, como juros, gráficos, etc. (DRUCK, 2003).

Não devemos somente ligar ensino de matemática e ser professor com teorias pedagógicas, pois de nada adianta o professor dispor de dezenas de técnicas, jogos, brincadeiras, enquanto o conteúdo e o embasamento matemático ficam jogados a um segundo plano. Faltam professores nas redes públicas de ensino, mas de nada adianta essas vagas serem preenchidas por pessoas incapacitadas.

Nos últimos 30 anos, implementou-se no Brasil a política da supervalorização de métodos pedagógicos em detrimento do conteúdo matemático na formação dos professores. Comprovamos, agora, os efeitos danosos, dessa política sob boa parte de nossos professores. Sem entender o conteúdo que lecionam, procuram facilitar o aprendizado usando técnicas pedagógicas e modismos de mérito questionável." (DRUCK, 2003) 
Citamos, previamente, o que se esperava de um professor de acordo com os Parâmetros Curriculares Nacionais, mas devemos levar em conta que a educação não pode estar sempre centralizada e baseada em situações concretas e cotidianas, elas devem ser um apoio e uma motivação para o estudo mais profundo da matemática no raciocínio lógico. Podemos usar a situação cotidiana de uma plantação para o cálculo de áreas, mas é imprescindível que os alunos saibam calcular a área de um trapézio, um pentágono, sem haver a necessidade de o problema estar contextualizado.

O professor do século XXI terá que se desafiar mais ainda, pois a ele caberá o papel de motivar em uma época em que as informações estão prontas e ao alcance de todos, desafiar e conscientizar os alunos de interessarem-se pelo novo, criando e rompendo limites na educação.

\section{CONSIDERAÇÕES FINAIS}

Pudemos desmitificar muitas coisas que ouvíamos e muitas coisas que pensávamos em relação à profissão de professor. Pensávamos que ser professor era entrar numa sala de aula e deparar-se com uma turma perfeita, onde todos obteriam um bom desempenho, ninguém conversaria e que quando eu falasse todos me escutassem e me entendessem prontamente. Infelizmente, constatei que isso é um mito. Ser professor é muito mais que postar-se na frente de um quadro e transmitir conteúdos sem nexo para o aluno. Ser professor é lidar com pessoas, pessoas que passam por momentos difíceis, pessoas que se cansam, que tem outras prioridades e anseios. Não existe uma turma perfeita e que estude somente matemática. Muitos que estão em sala de aula, vão porque são obrigados pelos pais, porque precisam comer a merenda... Poucos são os que, nessa jovem idade, sabem qual é a importância do estudo.

Aprendemos que ser professor é muito mais que calcular, é muito mais do que uma aplicar uma prova ou preencher uma lista de chamadas. Podemos não saber ainda o significado exato, mas sabemos que o que pensávamos antigamente mudou a partir desta vivência. 


\section{REFERÊNCIAS}

DRUCK, Suely. O drama do ensino de matemática. Folha de São Paulo - Caderno Sinapse 25/03/2003 São Paulo - SP

FREIRE, Paulo. Pedagogia do oprimido. $9^{\underline{a}}$ ed. São Paulo. Ed Paz e Terra 1987. PCN

IMENES, Luís M. P. Matemática 6aㅡ série. ${ }^{\underline{a}}$ ed. São Paulo - SP Ed. Scipione 1998

LUFT, Lia. Revista Veja /o4/20o6 - São Paulo - SP Editora Abril

ONAGA, Dulce. MORI, Iracema. Matemática - Idéias e Desafios. $9^{\underline{a}}$ ed. São Paulo - SP.

Ed. Saraiva 2000

ROGERS, Carl. Liberdade para aprender. $4^{\underline{a}}$ ed. Belo Horizonte. Ed. Interlivros, 1978 